\title{
Bounds on Co-Independent Liar's Domination in Graphs
}

\author{
K. Suriya Prabha $\mathbb{D}^{1},{ }^{\text {S. Amutha }} \mathbb{D}^{2}{ }^{2}$ N. Anbazhagan $\left(\mathbb{D},{ }^{1}\right.$ and Ismail Naci Cangul $\mathbb{D}^{3}$ \\ ${ }^{1}$ Department of Mathematics, Alagappa University, Karaikudi-630 003, Tamilnadu, India \\ ${ }^{2}$ Ramanujan Centre for Higher Mathematics (RCHM), Alagappa University, Karaikudi-630003, Tamilnadu, India \\ ${ }^{3}$ Department of Mathematics, Bursa Uludag University, Gorukle 16059, Turkey
}

Correspondence should be addressed to S. Amutha; amuthas@alagappauniversity.ac.in

Received 16 January 2021; Revised 22 February 2021; Accepted 3 March 2021; Published 20 March 2021

Academic Editor: Ghulam Shabbir

Copyright (c) 2021 K. Suriya Prabha et al. This is an open access article distributed under the Creative Commons Attribution License, which permits unrestricted use, distribution, and reproduction in any medium, provided the original work is properly cited.

\begin{abstract}
A set $S \subseteq V$ of a graph $G=(V, E)$ is called a co-independent liar's dominating set of $G$ if (i) for all $v \in V$, $\left|N_{G}[v] \cap S\right| \geq 2$, (ii) for every pair $u, v \in V$ of distinct vertices, $\left|\left(N_{G}[u] \cup N_{G}[v]\right) \cap S\right| \geq 3$, and (iii) the induced subgraph of $G$ on $V-S$ has no edge. The minimum cardinality of vertices in such a set is called the co-independent liar's domination number of $G$, and it is denoted by $\gamma_{\text {coi }}^{L R}(G)$. In this paper, we introduce the concept of co-independent liar's domination number of the middle graph of some standard graphs such as path and cycle graphs, and we propose some bounds on this new parameter.
\end{abstract}

\section{Introduction}

For notations and nomenclature, we refer [1]. Specifically, let $G=(V, E)$ be a graph with vertex set $V$ of order $p=|V|$ and edge set $E$ of size $q=|E|$. The diameter of $G$ is the greatest distance between any two vertices of $G$. The middle graph $M(G)$ is the derived graph obtained from $G$ by inserting a new vertex into every edge of $G$ and then joining these new vertices by edges which lie on the adjacent edges of $G$ [2]. Haynes et al. introduced the concept of domination in graphs [3].

A topological index is a real number related to a graph, which must be a structural invariant. The topological indices are a vital tool for quantitative structure activity relationship and quantitative structure property relationship. For more work on topological indices of a graph, refer recent papers $[4,5]$.

The concept of liar's domination was introduced by Panda and Paul in [6]. A graph $G=(V, E)$ admits a liar's dominating set if each of its connected components has at least three vertices. Several different domination parameters were studied in [7-12]. For references on liar's domination, see, for instance, $[2,13]$. A subset $S \subseteq V$ of a graph $G=(V, E)$ is called a co-independent liar's dominating set of $G$ if (i) for all $v \in V,\left|N_{G}[v] \cap S\right| \geq 2$, (ii) for every pair $u, v \in V$ of distinct vertices, $\left|\left(N_{G}[u] \cup N_{G}[v]\right) \cap S\right| \geq 3$, and (iii) the induced subgraph of $G$ on $V-S$ has no edge. The minimum cardinality of vertices in such a set is called the co-independent liar's domination number of $G$, and it is denoted by $\gamma_{\text {coi }}^{L R}(G)$. In this paper, we initiate the study of co-independent liar's domination in graphs.

\section{Co-Independent Liar's Domination in Graphs}

In this section, we first strengthen the co-independent liar's domination number of the middle graphs of some standard graphs. Eventually, some bounds will be obtained.

Theorem 1. Let $M\left(P_{p}\right)$ be the middle graph of a path graph $P_{p}$ of order $p$. Then,

$$
\gamma_{\mathrm{coi}}^{L R}\left(M\left(P_{p}\right)\right) \leq p+1 .
$$

Proof. Let $u_{1}, u_{2}, u_{3}, \ldots, u_{p}$ be the vertices of $P_{p}$ and also the vertices in $V\left(M\left(P_{p}\right)-P_{p}\right)$ be $u_{p+1}, u_{p+2}, u_{p+3}, \ldots, u_{2 p-1}$. Let $u \in V\left(M\left(P_{p}\right)\right)$. We prove that all the vertices of $M\left(P_{p}\right)$ get a co-independent liars dominating set arising in four cases:

(1) Case (i): let $u=u_{1}$. Recall that $\operatorname{deg}\left(u_{1}\right)=\operatorname{deg}\left(u_{p}\right)=1$. So, $N\left[u_{1}\right]=\left\{u_{1}, u_{p+1}\right\}$ in $M\left(P_{p}\right)$ and $\left|N\left[u_{1}\right]\right|=2$. Therefore, $|N[u] \cap S| \geq 2$, for all $u \in V\left(M\left(P_{p}\right)\right)$, and 
every set consisting of a vertex of $N\left[u_{1}\right]$ should be a component of $S$ and $\left\{u_{1}, u_{p+1}\right\} \in S$. So, $\left\{u_{2 p-1}, u_{p}\right\} \in S$ for $u=u_{p}$. Therefore, $\left\{u_{1}, u_{p+1}, u_{2 p-1}, u_{p}\right\} \in S$. Hence, $u_{2} \in V-S$, and it is independent.

(2) Case (ii): let $u$ be an element of $\left\{u_{2}, u_{3}, u_{4}, \ldots, u_{p-1}\right\}$. Then, $\operatorname{deg}\left(u_{2}\right)=\operatorname{deg}\left(u_{3}\right)=\cdots=\operatorname{deg}\left(u_{p-1}\right)=2$ and $N\left[u_{i}\right]=\left\{u_{i}, u_{p+i}, u_{p+i-1}\right\}$ for $i=2,3, \ldots, p-1$. Let $N\left[u_{j}\right] \cap N\left[u_{k}\right]=S_{j, k}$ for $k=2,3, \ldots, p-2$ and $j=k+1$. Then,

$$
\bigcup_{j, k=2}^{p-1} S_{j, k}=\left\{u_{p+2}, u_{p+3}, u_{p+4}, \ldots, u_{2 p-2}\right\} \in S .
$$

Therefore, $\left\{u_{1}, u_{p+1}, u_{p+2}, u_{p+3}, u_{p+4}, \ldots, u_{2 p-2}, u_{2 p-1}\right.$, $\left.u_{p}\right\} \in S$, and also, we get $\left|N\left[u_{j}\right] \cap S\right| \geq 2$ for all $u_{j}, j=1,2,3, \ldots, p$. Next, we demonstrate that $|(N[u] \cup N[v]) \cap S| \geq 3$ for every pair of distinct vertices. Note that $\left|N\left[u_{j}\right] \cap S\right|=2,\left|N\left[u_{k}\right] \cap S\right| \geq 3$, and $\left|N\left[u_{j}\right] \cap N\left[u_{k}\right]\right| \leq 1$. So, we have $\mid\left(N\left[u_{j}\right] \cup N\left[u_{k}\right]\right) \cap$ $S \mid \geq 3$ for $j, k=1,2, \ldots, p$. Therefore, $\left\{u_{2}, u_{3}, u_{4}, \ldots\right.$, $\left.u_{p-1}\right\} \in V-S$, and no two elements are adjacent in $V-S$.

(3) Case (iii): let $u=u_{p+1}$. Then, $\operatorname{deg}\left(u_{p+1}\right)=3$, and we can write $N\left[u_{p+1}\right]=\left\{u_{1}, u_{2}, u_{p+1}, u_{p+2}\right\}$. We have $N\left[u_{p+1}\right] \cap S=\left\{u_{1}, u_{p+1}, u_{p+2}\right\}$, and therefore, $\mid N$ $\left[u_{p+1}\right] \cap S \mid=3$. Let $u=u_{2 p-1}$. Then, $\operatorname{deg}\left(u_{2 p-1}\right)=3$ and $N\left[u_{2 p-1}\right]=\left\{u_{2 p-1}, u_{p-1}, u_{p}, u_{2 p-2}\right\}$. We get $N\left[u_{2 p-1}\right] \cap S=\left\{u_{2 p-2}, u_{2 p-1}, u_{p}\right\}$ and similarly $\left|N\left[u_{2 p-1}\right] \cap S\right|=3$.

(4) Case (iv): let $u$ be an element of $\left\{u_{p+2}, u_{p+3}, \ldots\right.$, $\left.u_{2 p-2}\right\}$ and $\operatorname{deg}\left(u_{p+2}\right)=\operatorname{deg}\left(u_{p+3}\right)=\cdots=\operatorname{deg}\left(u_{2 p-2}\right)=$ 4. Then,

lopenup-3

$$
\begin{aligned}
N\left[u_{p+2}\right] & =\left\{u_{p+2}, u_{p+1}, u_{2}, u_{3}, u_{p+3}\right\}, \\
N\left[u_{p+3}\right] & =\left\{u_{p+3}, u_{p+2}, u_{3}, u_{4}, u_{p+4}\right\}, \\
\cdot & \cdot \\
N\left[u_{2 p-2}\right] & =\left\{u_{2 p-2}, u_{2 p-3}, u_{p-2}, u_{p-1}, u_{2 p-1}\right\},
\end{aligned}
$$

and we obtain $\left|N\left[u_{j}\right] \cap S\right| \geq 3$ for $j=p+2, p+3, \ldots, 2 p-2$. Therefore, $\left\{u_{2}, u_{3}, u_{4}, \ldots, u_{p-1}\right\} \in V-S$, and for all $u v \in V-S, \quad u v \notin E$. Hence, $S=\left\{u_{1}, u_{p+1}, u_{p+2}, u_{p+3}, \ldots\right.$, $\left.u_{2 p-2}, u_{2 p-1}, u_{p}\right\}$ is a co-independent liar's dominating set of $M\left(P_{p}\right)$ and $\gamma_{\text {coi }}^{L R}\left(M\left(P_{p}\right)\right) \leq p+1$.

Theorem 2. Let $M\left(C_{p}\right)$ be the middle graph of a cycle graph. Then,

$$
\gamma_{\text {coi }}^{L R}\left(M\left(C_{p}\right)\right) \leq p
$$

Proof. Let the vertices of $C_{p}$ be $u_{1}, u_{2}, \ldots, u_{p}$ and $u_{p+1}, u_{p+2}, \ldots, u_{2 p}$ be the vertices of $V\left(M\left(C_{p}\right)-C_{p}\right)$. We investigate all vertices of $M\left(C_{p}\right)$ to get a co-independent liar's dominating set in two cases:

(1) Case (i): let $\operatorname{deg}\left(u_{i}\right)=2$ where $i=1,2,3, \ldots, p$, and let $u$ be an element of $\left\{u_{1}, u_{2}, \ldots, u_{p}\right\}$. Then, $S$ contains at least two vertices of $N\left[u_{i}\right]$ and it double dominates $u_{i}$ for $i=1,2,3, \ldots, p$. Hence,

$$
\begin{gathered}
N\left[u_{1}\right]=\left\{u_{1}, u_{p+1}, u_{p+2}\right\}, \\
N\left[u_{2}\right]=\left\{u_{2}, u_{p+2}, u_{p+3}\right\}, \\
\cdot \\
\cdot \\
N\left[u_{p-1}\right]=\left\{u_{p-1}, u_{2 p-1}, u_{2 p}\right\}, \\
N\left[u_{p}\right]=\left\{u_{p}, u_{2 p}, u_{p+1}\right\} .
\end{gathered}
$$

If $u v \in E\left(C_{p}\right)$, then we consider $N[u] \cap N[v]$. Let $N\left[u_{j}\right] \cap N\left[u_{k}\right]=S_{j, k}$, where $j, k=1,2,3, \ldots, p$. So, we have

$$
S_{1}=\bigcup_{j, k=1}^{p} S_{j, k}=\left\{u_{p+1}, u_{p+2}, \ldots, u_{2 p-2}, u_{2 p-1}, u_{2 p}\right\} \in S .
$$

Therefore, $S_{1}$ double dominates $u_{i}$ for $i=1,2, \ldots, p$. Clearly, we have $\left|\left(N\left[u_{j}\right] \cup N\left[u_{k}\right]\right) \cap S_{1}\right| \geq 3$ as $\left|N\left[u_{j}\right] \cap S_{1}\right|=2$ and $\left|N\left[u_{j}\right] \cap N\left[u_{k}\right]\right|=1$ for the vertices $u_{j}$ and $u_{k}$, where $u_{j} u_{k} \in E\left(C_{p}\right)$ for $j, k=1,2, \ldots, p$. Likewise, we have $\left|\left(N\left[u_{j}\right] \cup N\left[u_{k}\right]\right) \cap S_{1}\right|=4 \geq 3$ as $\left|N\left[u_{j}\right] \cap S_{1}\right|=2$ and $\left|N\left[u_{j}\right] \cap N\left[u_{k}\right]\right|=0$ for the vertices $u_{j}$ and $u_{k}$, where $u_{j} u_{k} \notin E\left(C_{p}\right)$ for $j, k=1,2,3, \ldots, p$. Therefore, $S_{1}$ triple dominates $u_{i}$ for $i=1,2,3, \ldots, p$. Hence, $\left\{u_{1}, u_{2}, \ldots, u_{p}\right\} \in V-S$, and no two elements in $V-S$ can form an edge.

(2) Case (ii): let $\operatorname{deg}\left(u_{j}\right)=4$, where $j=p+1, p+2, \ldots, 2 p$, and let $u$ be an element of $\left\{u_{p+1}, \ldots, u_{2 p}\right\}$.

$$
\begin{aligned}
& N\left[u_{p+1}\right]=\left\{u_{p+1}, u_{p}, u_{1}, u_{2 p}, u_{p+2}\right\}, \\
& N\left[u_{p+2}\right]=\left\{u_{p+2}, u_{1}, u_{2}, u_{p+1}, u_{p+3}\right\},
\end{aligned}
$$

$$
\begin{gathered}
N\left[u_{2 p-1}\right]=\left\{u_{2 p-1}, u_{p-2}, u_{p-1}, u_{2 p-2}, u_{2 p}\right\} \\
N\left[u_{2 p}\right]=\left\{u_{2 p}, u_{p-1}, u_{p}, u_{2 p-1}, u_{p+1}\right\} .
\end{gathered}
$$

We obtain $\left|N\left[u_{j}\right] \cap S_{1}\right|=3$ for $j=p+1, p+2, \ldots, 2 p$. Therefore, $S_{1}$ triple dominates $u_{j}$ for $j=p+1, p+2, \ldots, 2 p$. So, $\left\{u_{1}, u_{2}, \ldots, u_{p}\right\} \in V-S$. For every $u, v \in V-S, u v \notin E$. 
Hence, $S=S_{1}=\left\{u_{p+1}, u_{p+2}, \ldots, u_{2 p}\right\}$ is a co-independent liar's dominating set of $M\left(C_{p}\right)$ and $\gamma_{\text {coi }}^{L R}\left(M\left(C_{p}\right)\right) \leq p$.

Note 1. Let $M\left(W_{p}\right)$ be the middle graph of a wheel graph, then a co-independent liar's dominating set does not exist.

We have the following lower bound on co-independent liar's domination number in terms of the diameter of a graph.

Theorem 3. Let $G$ be a graph of order $p \geq 4$. Then,

$$
\gamma_{\mathrm{coi}}^{L R}(G) \geq \frac{3}{4}(\operatorname{diam}(G)+2)
$$

Proof. Let $S$ be a $\gamma_{\text {coi }}^{L R}(G)$ set. We employ an induction on the number $r$ of components of $G[S]$ to indicate that $\gamma_{\text {coi }}^{L R}(G) \geq \operatorname{diam}(G)-r+2$, and hence the result will follow: suppose that $G[S]$ has precisely one component, that is, $G[S]$ is connected and $|S| \geq 3$. We show that the distance between any pair of vertices in $G$ is atmost $|S|-1$. Let $y_{1}$ and $y_{2}$ be two distinct vertices of $G$. If $y_{1}, y_{2} \in S$, then $d_{G}\left(y_{1}, y_{2}\right) \leq \operatorname{diam}(G[S]) \leq|S|-1$. Next, assume that $y_{1} \notin S$ and $y_{2} \notin S$. It may be verified that $\left|N\left[y_{1}\right] \cap S\right| \geq 2$. Since $y_{1} \notin S$, there are at least two vertices $y_{i}$ and $y_{j}$ in $N\left(y_{1}\right) \cap S$. Similarly, it may be concluded that there are two vertices $y_{i}^{\prime}$ and $y_{j}^{\prime}$ in $N\left(y_{2}\right) \cap S$. If $\left\{y_{i}, y_{j}\right\} \cap\left\{y_{i}^{\prime}, y_{j}^{\prime}\right\} \neq \phi$, then $d\left(y_{1}, y_{2}\right) \leq|S|-1 \quad$ since $\quad|S| \geq 3$. Suppose that $\left\{y_{i}, y_{j}\right\} \cap\left\{y_{i}^{\prime}, y_{j}^{\prime}\right\}=\phi$. Assume, without loss of generality, that $\quad d_{G[S]}\left(y_{i}, y_{i}^{\prime}\right)=\min \left\{d_{G[S]}(v, w): v \in\left\{y_{i}, y_{j}\right\}, w \in\right.$ $\left.\left\{y_{i}^{\prime}, y_{j}^{\prime}\right\}\right\}$. It is easy to verify that $d_{G[S]}\left(y_{i}, y_{i}^{\prime}\right) \leq|S|-3$. Now,

$$
\begin{aligned}
d_{G}\left(y_{1}, y_{2}\right) \leq d_{G}\left(y_{1}, y_{i}\right) & +d_{G[S]}\left(y_{i}, y_{i}^{\prime}\right)+d_{G}\left(y_{i}^{\prime}, y_{2}\right) \\
& \leq 1+(|S|-3)+1=|S|-1 .
\end{aligned}
$$

Next, we take $y_{1} \notin S$ and $y_{2} \in S$. As before, there are two vertices $y_{i}$ and $y_{j}$ in $N\left(y_{1}\right) \cap S$. If $\left\{y_{i}, y_{j}\right\} \cap\left\{y_{2}\right\} \neq \phi$, then $d_{G}\left(y_{1}, y_{2}\right)=1 \leq|S|-1$ as $|S| \geq 3$. Let $\left\{y_{i}, y_{j}\right\} \cap\left\{y_{2}\right\}=\phi$. Without loss of generality, we might assume that $d_{G[S]}\left(y_{i}, y_{2}\right)=\min \left\{d_{G[S]}\left(v, y_{2}\right): v \in\left(y_{i}, y_{j}\right)\right\}$. Then, $d_{G}(y$ $\left.{ }_{1}, y_{2}\right) \leq d_{G}\left(y_{1}, y_{i}\right)+d_{G[S]}\left(y_{i}, y_{2}\right) \leq 1+(|S|-2)=|S|-1$.

Suppose that the result is true for the number of components of $G[S]$ which are less than $r$. Let $S=\cup_{i=1}^{r} S_{i}$, where $G\left[S_{i}\right]$ is the component of $G[S]$ for $i=1,2,3, \ldots, r$. Let $V_{i}$ be the set of all vertices of $V(G)-S$ with at least two neighbors in $L_{i}$ and $G_{i}=G\left[V_{i} \cup S_{i}\right]$. If for every $m, n \in V-S$, then $m n \notin E(G)$. In order to maximize the diameter, without loss of generality, we may assume that, for $i=1,2, \ldots, r-1$, $\left|N\left(G_{i}\right) \cap N\left(G_{i+1}\right)\right|=1$ and for every $j>i+1$, $\left|N\left(G_{i}\right) \cap N\left(G_{j}\right)\right|=0$. Let $N\left(G_{i}\right) \cap N\left(G_{i+1}\right)=\left\{v_{i}\right\}$ for $i=1,2, \ldots, r-1$. Let $p, q$ be two distinct vertices of $V(G)$ with $d_{G}(p, q)=\operatorname{diam}(G)$. Then,

$$
\begin{aligned}
d_{G}(p, q) & \leq \sum_{i=1}^{r} \operatorname{diam}\left(G_{i}\right)+d_{G}\left(G_{1}, v_{1}\right)+d_{G}\left(v_{1}, G_{2}\right)+d_{G}\left(G_{2}, v_{2}\right)+\cdots+d_{G}\left(v_{r-1}, G_{r}\right) \\
& =\sum_{i=1}^{r} \operatorname{diam}\left(G_{i}\right)+2(r-1) .
\end{aligned}
$$
Hence,

By induction, we find that $\operatorname{diam}\left(G_{i}\right) \leq\left|S_{i}\right|-1, \forall 1 \leq i \leq r$.

$$
d_{G}(p, q) \leq \sum_{i=1}^{r}\left(\left|S_{i}\right|-1\right)+2(r-1) \text {. }
$$

Hence,

$$
d_{G}(p, q) \leq|S|+r-2 \text {. }
$$

Therefore, $\gamma_{\text {coi }}^{L R}(G) \geq \operatorname{diam}(G)-r+2$.

We now study some bounds on co-independent liar's domination number in terms of the components of a cut vertex deleted graph.

Theorem 4. Let $x$ be a cut vertex of a graph $G$ and $T_{1}, T_{2}, T_{3}, \ldots, T_{m}$ be the components of $G-x$. If $\left|T_{j}\right| \geq 2$ and $G_{j}=T_{j} \cup\{x\}$ for $1 \leq j \leq m$, then

$$
\sum_{j=1}^{m} \gamma_{\mathrm{coi}}^{L R}\left(G_{j}\right)-(2 m-1) \leq \gamma_{\mathrm{coi}}^{L R}(G) \leq \sum_{j=1}^{m} \gamma_{\mathrm{coi}}^{L R}\left(G_{j}\right) .
$$

Proof. First, we show that $\sum_{j=1}^{m} \gamma_{\text {coi }}^{L R}\left(G_{j}\right)-(2 m-1) \leq$ $\gamma_{\text {coi }}^{L R}(G)$. Let $S$ be a $\gamma_{\text {coi }}^{L R}(G)$ set and $S_{j}=S \cap V\left(G_{j}\right)$ for $j=1,2,3, \ldots, m$. If $x \in S$, we have $\sum_{j=1}^{m}\left|S_{j}\right|=\gamma_{\text {coi }}^{L R}(G)+m$ and if $x \notin S$, then $\sum_{j=1}^{m}\left|S_{j}\right|=\gamma_{\text {coi }}^{L R}(G)$. Clearly, for every vertex, $u \in V\left(G_{j}\right) /\{x\}, \quad(j=1,2,3, \ldots, m), \quad N_{G_{j}}[u] \cap S_{j}=$ $N_{G}[u] \cap S$, and $\left|N_{G_{j}}[u] \cap S_{j}\right| \geq 2$. Moreover, for any pair $u, v \in V\left(G_{j}\right) /\{x\},(j=1,2,3, \ldots, m),\left|(N[u] \cup N[v]) \cap S_{j}\right|=$ $|(N[u] \cup N[v]) \cap S| \geq 3$, and also the set $V\left(G_{j}\right)-S_{j}$ is independent. We have to consider following two cases:

Case (i): let $x \in S$. For any $1 \leq j \leq m$, there is at least one vertex $r_{j} \in N(x) \cap S_{j}$, so $\left|N[x] \cap S_{j}\right| \geq 2$. Since each vertex $z \in V\left(G_{j}\right) /\left(N_{G_{j}}(x) \cap N\left(r_{j}\right)\right)$ should be double dominated by $S_{j}$, there is at least a vertex $w \in N(z) \cap S_{j}, \quad w \neq r_{j}$. Therefore, for each vertex $z \in V\left(G_{j}\right)-\left(N_{G_{j}}(x) \cap N\left(r_{j}\right)\right)$,

$$
\left|\left(N_{G_{j}}[x] \cup N[z] \cap S_{j}\right)\right| \geq\left|\left\{x, r_{j}, w\right\}\right|=3 .
$$


Hence, let $y \in N_{G_{j}}(x) \cap N\left(r_{j}\right)$ and $S_{j}^{\prime}=S_{j} \cup\{z\}$. So, for every vertex $y \in N_{G_{j}}(x) \cap N\left(r_{j}\right)$,

$$
\left|\left(N_{G_{j}}[x] \cup N[y] \cap S_{j}^{\prime}\right)\right| \geq\left|\left\{x, r_{j}, z\right\}\right|=3 .
$$

and for every $r, s \in V\left(G_{j}\right)-S_{j}, r s \notin E\left(G_{j}\right)$. Hence, $S_{j}^{\prime}$ is a co-independent liar's dominating set for each $G_{j}$, and therefore,

$$
\gamma_{\text {coi }}^{L R}\left(G_{j}\right) \leq\left|S_{j}^{\prime}\right|=\left|S_{j}\right|+1 .
$$

For each vertex $t \in N(x) \cap V\left(G_{j}\right), t \notin S_{j}$. Repeating these, each vertex $z \in V\left(G_{j}\right) /\{x\}$ should be double dominated by $S_{j}$. In such a component, there is at least one vertex $z \prime \in N(z) \cap S_{j}$. Let $S_{j}^{\prime}=S_{j} \cup\{t\}$ for each vertex $t \in N(x) \cap V\left(G_{j}\right), t \notin S_{j}$. Hence, for every vertex $z \in V\left(G_{j}\right) /\{x\}$,

$$
\left|\left(N_{G_{j}}[x] \cup N[z]\right) \cap S_{j}^{\prime}\right| \geq|\{x, t, z \prime\}|=3 .
$$

Also,

$$
\left|N_{G_{j}}[x] \cap S_{j}^{\prime}\right| \geq|\{x, t\}|=2 .
$$

and no two vertices can be adjacent in $V\left(G_{j}\right)-S_{j}$. There is at least one vertex $r_{j} \in N(x) \cap S_{j}$. As before, for $z \in V\left(G_{j}\right) /\left(N_{G_{j}}(x) \cap N\left(r_{j}\right)\right)$, we have

$$
\left|\left(N_{G_{j}}[x] \cup N[z]\right) \cap S_{j}\right| \geq\left|\left\{x, r_{j}, w\right\}\right|=3 .
$$

Let $S_{j}^{\prime}=S_{j} \cup\{z\}$. For each vertex $y \in N_{G_{j}}(x) \cap N\left(r_{j}\right)$, we have

$$
\left|\left(N_{G_{j}}[x] \cup N[y]\right) \cap S_{j}^{\prime}\right| \geq\left|\left\{x, r_{j}, z\right\}\right|=3 .
$$

Thus, for each pair of vertices in $V\left(G_{j}\right)-S_{j}$ for $j=1,2,3, \ldots, m, S_{j}^{\prime}$ is a co-independent liar's dominating set and

$$
\gamma_{\text {coi }}^{L R}(G) \leq\left|S_{j}^{\prime}\right|=\left|S_{j}\right|+1 .
$$

Thus, in any case, as $x \in S, S^{\prime}$ is a co-independent liar's dominating set for $G_{j}(1 \leq j \leq m)$. Thus,

$$
\begin{aligned}
\sum_{j=1}^{m} \gamma_{\mathrm{coi}}^{L R}\left(G_{j}\right) & \leq \sum_{j=1}^{m}\left|S_{j}^{\prime}\right| \\
& \leq \sum_{j=1}^{m}\left(\left|S_{j}\right|+1\right) \\
& =\sum_{j=1}^{m}\left|S_{j}\right|+m \\
& =\gamma_{\mathrm{coi}}^{L R}(G)+m-1+m .
\end{aligned}
$$

So, $\sum_{j=1}^{m} \gamma_{\mathrm{coi}}^{L R}\left(G_{j}\right)-(2 m-1) \leq \gamma_{\mathrm{coi}}^{L R}(G)$.

Case (ii): let $x \notin S$. Because $|N[x] \cap S| \geq 2$, there is at least one component. Without loss of generality, we might assume that $r_{1} \in N(x) \cap S_{1}$. Let $S_{j}^{\prime}=S_{j} \cup\left\{x, r_{j}\right\}$, where $r_{j}$ is an arbitrary vertex in $N(x) \cap V\left(G_{j}\right),(j=1,2,3, \ldots, m)$. As for every vertex $z \in V\left(G_{j}\right) /\{x\},\left|N[z] \cap S_{j}\right| \geq 2$, there are at least two vertices $w, y \in N[z] \cap S_{j}$. So, for each $z \in V\left(G_{j}\right) /\{x\}$, we have

$$
\left|\left(N[z] \cup N_{G_{j}}[x]\right) \cap S_{j}^{\prime}\right| \geq|\{w, y, x\}|=3,
$$

and $\quad\left|N[x] \cap S_{j}^{\prime}\right| \geq\left|\left\{x, r_{j}\right\}\right|=2$, and for every $r, s \in V\left(G_{j}\right)-S_{j}, r s \notin E\left(G_{j}\right)$. Therefore,

$$
\begin{aligned}
\sum_{j=1}^{m} \gamma_{\mathrm{coi}}^{L R}\left(G_{j}\right) & \leq \sum_{j=1}^{m}\left|S_{j}^{\prime}\right| \\
& \leq \sum_{j=1}^{m}\left(\left|S_{j}\right|+2\right)-1 \\
& =\sum_{j=1}^{m}\left|S_{j}\right|+2 m-1 \\
& =\gamma_{\mathrm{coi}}^{L R}(G)+2 m-1 .
\end{aligned}
$$

Similarly, the second inequality can be proven.

We now characterize the graphs according to the sensitivity of a co-independent liar's dominating set versus a cut edge.

Theorem 5. Let $e=x y$ be a cut edge (bridge) in a graph $G$ and $G_{1}$ and $G_{2}$ be the components of $G-e$. If $\left|V\left(G_{1}\right)\right| \geq 4$ and $\left|V\left(G_{2}\right)\right| \geq 4$, then

$$
\gamma_{\text {coi }}^{L R}\left(G_{1}\right)+\gamma_{\text {coi }}^{L R}\left(G_{2}\right)-2 \leq \gamma_{\text {coi }}^{L R}(G) \leq \gamma_{\text {coi }}^{L R}\left(G_{1}\right)+\gamma_{\text {coi }}^{L R}\left(G_{2}\right) .
$$

Proof. Let $S$ be a co-independent liar's dominating set and $S_{1}=S \cap G_{1}, S_{2}=S \cap G_{2}$. When $x, y \notin S$, deleting the edge $x y$ does not change the sizes of co-independent liar's dominating sets of $G_{1}$ and $G_{2}$. Assume that $x \in S$ and $y \notin S$. Then, clearly, for every component of $S$ having a minimum of four vertices, we can assume that there are two vertices $x^{\prime} \in N(x) \cap S_{1}$ and $x^{\prime \prime} \in\left(N(x) \cap S_{1}\right) \cup\left(N(x /) \cap S_{1}\right) /\left\{x, x^{\prime}\right\}$ and $V\left(G_{1}\right)-S_{1}$ has no edge. Similarly, there are two vertices $y^{\prime} \in N(y) \cap S_{2}, \quad y^{\prime \prime} \in\left(N(y) \cap S_{2}\right) \cup\left(\left(N(y \prime) \cap S_{2}\right) /\left\{y, y^{\prime}\right\}\right)$, and also, the subgraph induced by $V\left(G_{2}\right)-S_{2}$ is independent. Let $S_{1}^{\prime}=S_{1}$ and $S_{2}^{\prime}=S_{2} \cup\{y\}$. Then, $S_{1}^{\prime}$ and $S_{2}^{\prime}$ form coindependent liar's dominating sets for $G_{1}$ and $G_{2}$ and $\left|S_{1}^{\prime}\right|+\left|S_{2}^{\prime}\right|-1 \leq|S|$.

$$
\left|S_{1}^{\prime}\right|+\left|S_{2}^{\prime}\right|-1 \leq|S| .
$$

Next, suppose that both $x$ and $y \in S$. Then, there is a vertex $x^{\prime} \in N(x) \cap S_{1}$ or $y^{\prime} \in N(y) \cap S_{2}$. Without loss of generality, we might assume that it is $x$ '. Let $S_{1}^{\prime}=S_{1} \cup\left\{x^{\prime \prime}\right\}$, where $\quad x^{\prime \prime} \in\left(N(x) \cap G_{1} \cup\left(N(x) \cap G_{1} /\{x, x)\right\} \quad\right.$ and 
$S_{2}^{\prime}=S_{2} \cup\left\{y^{\prime}, y^{\prime \prime}\right\}$, where $\quad y^{\prime} \in N(y) \cap G_{2} \quad$ and $y^{\prime \prime} \in\left(N(y) \cap G_{2}\right) \cup\left(\left(N\left(y^{\prime}\right) \cap G_{2}\right) /\left\{y, y^{\prime}\right\}\right)$. Therefore, $S_{1}^{\prime}, S_{2}^{\prime}$ form co-independent liar's dominating sets of $G_{1}$ and $G_{2}$ and

$$
\left|S_{1}^{\prime}\right|+\left|S_{2}^{\prime}\right|-2 \leq|S|
$$

The right side inequality follows from the fact that the union of the $\gamma_{\text {coi }}^{L R}\left(G_{1}\right)$ set and the $\gamma_{\text {coi }}^{L R}\left(G_{2}\right)$ set forms a coindependent liar's dominating set for $G$.

Theorem 6. Let $G$ and $\bar{G}$ be connected and $|V(G)|=p$, $p \geq 5$, then $16 \leq \gamma_{\text {coi_lr }}(G) \gamma_{\text {coi_lr }}(\bar{G}) \leq p^{2}$.

Proof. The upper bound is obvious. We established the lower bound. Let $G$ be a connected graph of order $p$ such that $\bar{G}$ is connected. Clearly, $\gamma_{\text {coi_ll }}(G) \geq 3$ and $\gamma_{\text {coi_ll }}(\bar{G}) \geq 3$. The result is obvious if $\min \left\{\gamma_{\text {coi_ll }}(G), \gamma_{\text {coi_ll }}(\bar{G})\right\} \geq 4$. Hence, let $\min \left\{\gamma_{\text {coi_ll }}(G), \gamma_{\text {coi_ll }}(\bar{G})\right\}=4$. Without loss of generality, assume that $\gamma_{\text {coi_lr }}(G)=4$. We show that $\gamma_{\text {coi_lr }}(\bar{G}) \geq 4$. Let $S=\left\{u_{1}, u_{2}, u_{3}, u_{4}\right\}$ be a $\gamma_{\text {coi_ll }}(G)$ set and $S$ ' be a $\gamma_{\text {coi_lr }}(\bar{G})$ set. We partition the set $V(G) / S$ into two sets $M=$ $\{y \in V(G) / S:|N(y) \cap S|=3\} \quad$ and $\quad N=\{y \in V(G) / S$ : $|N(y) \cap S|=4\}$. Note that $|M|=4$. Since $\bar{G}$ is connected and none of the vertices in $N$ are adjacent to any vertex in $S$ in $\bar{G}$, we can deduce that $|M| \geq 4$. Hence, $|M|=4$. Let $M=\left\{v_{1}, v_{2}, v_{3}, v_{4}\right\}$, where $v_{j}$ is not adjacent $u_{j}$ in $G$ for $j=1,2,3,4$. Since $G[S]$ is connected, we may think that $\left\{u_{1}, u_{3}\right\} \subseteq N\left(u_{2}\right)$. Now, the only vertex adjacent to $u_{2}$ in $\bar{G}$ is $v_{2}$, so $\left\{v_{2}, u_{2}\right\} \in S^{\prime}$. In addition, according to the coindependent liar's domination which has been discussed, $\left|\left\{u_{1}, v_{1}, u_{3}, v_{3}\right\} \cap S_{\prime}\right| \geq 3$. Therefore, $\gamma_{\text {coi_ll }}(\bar{G})=\left|S_{\prime}\right| \geq 4$.

Theorem 7. Let $M(T)$ be the middle graph of a tree with $p \geq 3$. Then, $\gamma_{\text {coi_l } r}(M(T)) \leq p+2$.

Proof. Let the vertices of $T$ be $u_{1}, u_{2}, u_{3}, \ldots, u_{p}$ and $u_{p+1}, u_{p+2}, u_{p+3}, \ldots, u_{2 p-1}$ be the vertices of $V(M(T))$. We prove that all vertices of $M(T)$ arise in four cases to get a coindependent liars dominating set:

(i) Case (i): if $\operatorname{deg}\left(u_{i}\right)=1$, that is, $u_{i}$ is a pendant vertex in $V(M(T))$, then $N\left[u_{i}\right]=\left\{u_{i}, u_{p+i}\right\}$ in $M(T)$ and $\left|N\left[u_{i}\right]\right|=2$. Therefore, $\quad\left|N\left[u_{i}\right] \cap S\right| \geq 2$, $\forall u_{i} \in V(M(T))$, and all the vertices of $N\left[u_{i}\right]$ should be components of $S, \quad\left\{u_{i}, u_{p+i}\right\} \in S$. So, $\left\{u_{2 p-1}, u_{p}\right\} \in S$ for $u=u_{p}$. Therefore, $\left\{u_{i}, u_{p+i}\right.$, $\left.u_{2 p-i}, u_{p}\right\} \in S$.

(ii) Case (ii): if $\operatorname{deg}\left(u_{i}\right)=2$ in $V(M(T))$, then $N\left[u_{i}\right]=$ $\left\{u_{i}, u_{p+i}, u_{p+i-1}\right\} \quad$ for $i=2,3, \ldots, p-1$. Let $N\left[u_{j}\right] \cap N\left[u_{k}\right]=S_{j, k}$, where $k=2,3, \ldots, p-2$ and $j=k+1$. Then, $\cup_{j, k=2}^{p-1} S_{j, k}=\left\{u_{p+2}, u_{p+3}, u_{p+4}, \ldots\right.$, $\left.u_{2 p-2}\right\} \in S$. Therefore, $\left\{u_{1}, u_{p+1}, u_{p+2}, u_{p+3}, u_{p+4}, \ldots\right.$, $\left.u_{2 p-2}, \quad u_{2 p-1}, u_{p}\right\} \in S$ and $\left|N\left[u_{j}\right] \cap S\right| \geq 2, \forall u_{j}, j=$

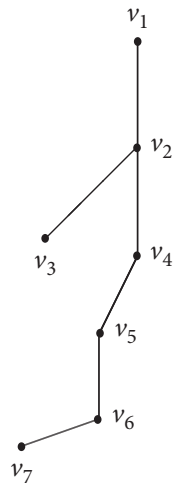

(a)

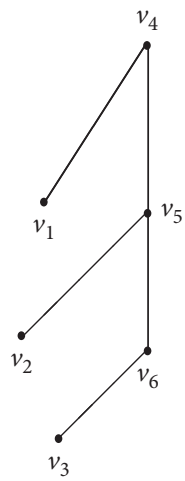

(b)
Figure 1: Trees for Remark 1.

$1,2,3, \ldots, p$. Next, we demonstrate that $\mid(N[u] \cup$ $N[v]) \cap S \mid \geq 3$ for every pair of distinct vertices. We see that $\left|N\left[u_{j}\right] \cap S\right|=2, \quad\left|N\left[u_{k}\right] \cap S\right| \geq 3$, and $\left|N\left[u_{j}\right] \cap N\left[u_{k}\right]\right| \leq 1$. So, we have $\mid\left(N\left[u_{j}\right] \cup N\right.$ $\left.\left[u_{k}\right]\right) \cap S \mid \geq 3$, where $j, k=1,2, \ldots, p$. Therefore, $\left\{u_{2}, u_{3}, u_{4}, \ldots, u_{p-1}\right\} \in V-S$, and no two elements are adjacent in $V-S$.

(iii) Case (iii): if $\operatorname{deg}\left(u_{i}\right)=3$ in $V(M(T))$, then $N\left[u_{p+i}\right]=\left\{u_{1}, u_{2}, u_{p+i}, u_{p+i+1}\right\}$. We have $N\left[u_{p+i}\right] \cap$ $S=\left\{u_{1}, u_{p+i}, u_{p+i+1}\right\}$ and $\left|N\left[u_{p+i}\right] \cap S\right|=3$. Let $u$ be $u_{2 p-1}$. Then, $\operatorname{deg}\left(u_{2 p-1}\right)=3$ and $N\left[u_{2 p-1}\right]=\left\{u_{2 p-1}\right.$, $\left.u_{p-1}, u_{p}, u_{2 p-2}\right\}$. We get $N\left[u_{2 p-1}\right] \cap S=\left\{u_{2 p-2}\right.$, $\left.u_{2 p-1}, u_{p}\right\}$ and $\left|N\left[u_{2 p-1}\right] \cap S\right|=3$.

(iv) Case (iv): if $\operatorname{deg}\left(u_{i}\right)=4$ in $V(M(T))$, then

$$
\begin{aligned}
& N\left[u_{p+2}\right]=\left\{u_{p+2}, u_{p+1}, u_{2}, u_{3}, u_{p+3}\right\}, \\
& N\left[u_{p+3}\right]=\left\{u_{p+3}, u_{p+2}, u_{3}, u_{4}, u_{p+4}\right\},
\end{aligned}
$$

$$
N\left[u_{2 p-2}\right]=\left\{u_{2 p-2}, u_{2 p-3}, u_{p-2}, u_{p-1}, u_{2 p-1}\right\}
$$

We obtain $\left|N\left[u_{j}\right] \cap S\right| \geq 3$, where $j=p+2, p+3, \ldots$, $2 p-2$. Therefore, $\left\{u_{2}, u_{3}, u_{4}, \ldots, u_{p-1}\right\} \in V-S$, and for all $u v \in V-S, \quad u v \notin E$. Hence, $S=\left\{u_{1}, u_{p+1}, u_{p+2}, u_{p+3}, \ldots\right.$, $\left.u_{2 p-2}, u_{2 p-1}, u_{p}\right\}$ is the co-independent liar's dominating set of $M(T)$ and $\gamma_{\text {coi_ll }}(M(T)) \leq p+2$.

Remark 1. (i) A tree is a co-independent liar's dominating set. Indeed in Figure 1(a), let $V(G)=\left\{v_{1}, v_{2}, v_{3}, v_{4}, v_{5}, v_{6}, v_{7}\right\}$. If we take $S=\left\{v_{1}, v_{2}, v_{3}, v_{5}, v_{6}, v_{7}\right\}$, then $V-S=\left\{v_{4}\right\}$ which is a co-independent liar's dominating set. (ii) Coindependent liar's dominating set need not exist for all trees. For example, in Figure 1(b), let $V(G)=\left\{v_{1}, v_{2}, v_{3}, v_{4}, v_{5}, v_{6}\right\}$. 
Suppose we take the co-independent liar's dominating set $S=\left\{v_{1}, v_{2}, v_{3}, v_{4}, v_{5}, v_{6}\right\}$. But $V-S=\phi$ which satisfies conditions (i) and (ii) but not (iii).

(i) For all $v \in V,\left|N_{G}[v] \cap S\right| \geq 2$

(ii) For every pair $u, v \in V$ of distinct vertices, $\left|\left(N_{G}[u] \cup N_{G}[v]\right) \cap S\right| \geq 3$

(iii) The induced subgraph of $G$ on $V-S$ has no edge

\section{Conclusion}

In this paper, the co-independent liar's domination number of the middle graphs of some graph classes such as path and cycle graphs is calculated. Also, some general results and bounds on the co-independent liar's domination number of graphs are obtained. It has been shown that no general result can be obtained for trees, unicyclic, bicyclic, and tricyclic graphs in terms of co-independent liar's domination number.

\section{Data Availability}

No data were used to support this study.

\section{Conflicts of Interest}

The authors declare that they have no conflicts of interest.

\section{References}

[1] F. Harary, Graph Theory, Addison-Wesley, Boston, MA, USA, 1972.

[2] D. D. Durgun and F. N. Altundag, "Liars domination in graphs," Bulletin of the International Mathematical Virtual Institute, vol. 7, pp. 407-415, 2017.

[3] T. W. Haynes, S. T. Hedetniemi, and P. J. Slater, Fundamentals of Domination in Graphs, Marcel Dekker Inc., New York, NY, USA, 1998.

[4] A. Hussain, M. Numan, N. Naz, S. I. Butt, A. Aslam, and A. Fahad, "On topological indices for new classes of benes network," Journal of Mathematics, vol. 2021, Article ID 6690053, 7 pages, 2021.

[5] J. B. Liu and X. F. Pan, "Minimizing Kirchhoff index among graphs with a given vertex bipartiteness," Applied Mathematics and Computation, vol. 291, pp. 84-88, 2016.

[6] B. S. Panda and S. Paul, "Liar's domination in graphs: complexity and algorithm," Discrete Applied Mathematics, vol. 161, no. 7-8, pp. 1085-1092, 2013.

[7] S. Amutha and N. Sridharan, " $\gamma_{t}$ - graph of a graph G," Ramanujan Mathematical Society, Discrete Mathematics, vol. 7, pp. 255-262, 2006.

[8] S. Amutha and N. Sridharan, "A note on sets $V_{t}^{-}, V_{t}^{0}$, $V_{t}^{+}$, of a simple graph $G$ with $\delta(G) \geq 2$," Journal of Pure and Applied Mathematics: Advances and Applications, vol. 9, no. 2, pp. 69-79, 2013.

[9] N. Sridharan, S. Amutha, and S. B. Rao, "Induced sub graphs of a gamma graphs," Discrete Mathematics Algorithm and Applications, vol. 5, no. 3, pp. 1-5, 2013.

[10] N. Sridharan and S. Amutha, "Characterization of total very excellent trees," Mathematics and Computing, vol. 139, no. 18, pp. 265-275, 2015.
[11] K. Suriya Prabha and S. Amutha, "Edge Mean labeling of a regular graphs," International Journal of Mathematics Trends and Technology, vol. 53, no. 5, pp. 343-352, 2018.

[12] K. Suriya Prabha and S. Amutha, "Split domination number of a congruent dominating graphs," International Journal of Pure and Applied Mathematics, vol. 119, no. 12, pp. 14633$14642,2018$.

[13] A. Alimadadi, N. Jafari Rad, and D. A. Mojdeh, "Various bounds for liar's domination number," Discussiones Mathematicae Graph Theory, vol. 36, no. 3, pp. 629-641, 2016. 